\title{
Role of RNA primers in initiation of minus-strand and plus-strand DNA synthesis of the yeast retrotransposon Ty1
}

\author{
S Friant ${ }^{\mathrm{a}}$, T Heyman $^{\mathrm{b}}$, FX Wilhelm ${ }^{\mathrm{a}}$, M Wilhelm $^{\mathrm{a}}$ \\ ${ }^{\mathrm{a}}$ UPR 9002 CNRS, Institut de Biologie Moléculaire et Cellulaire, 15, rue René-Descartes, 67084 Strasbourg cedex; \\ ${ }^{\mathrm{b}}$ UMR 216 CNRS, Institut Curie-Biologie, Centre Universitaire, 91405 Orsay cedex, France
}

(Received 29 March 1996; accepted 28 June 1996)

\begin{abstract}
Summary - The Ty 1 retrotransposon of the yeast Saccharomyces cerevisiae is a long terminal repeat mobile genetic element that transposes through an RNA intermediate. Initiation of minus-strand and plus-strand DNA synthesis are two critical steps during reverse transcription of the retrotransposon genome. Initiation of minus-strand DNA synthesis of the Tyl element is primed by the cytoplasmic initiator methionine tRNA base paired to the primer binding site near the 5 ' end of the genomic RNA. A structural probing study of the primer tRNA-Ty 1 RNA binary complex reveals that besides interactions between the primer binding site and the last 10 nucleotides at the $3^{\prime}$ end of the primer tRN $A$, three short regions of Ty1 RNA named box 0 , box 1 and box 2.1 interact with the T and D stems and loops of the primer tRNA. Some in vivo results underline the functional importance of the nucleotide sequence of the boxes and suggest that extended interactions between genomic Ty1 RNA and the primer tRNA play a role in the reverse transcription pathway. Plus-strand DNA synthesis is initiated from an RNase $\mathrm{H}$ resistant oligoribonucleotide spanning a purine-rich sequence, the polypurine tract (PPT). Two sites of initiation located at the $5^{\prime}$ boundary of the $3^{\prime}$ long terminal repeat (PPT1) and near the middle of the TyB (pol) gene in the integrase coding sequence (PPT2) have been identified in the genome of Tyl. The two PPTs have an identical sequence, TGGGTGGTA. Mutations replacing purines by pyrimidines in this sequence significantly diminish or abolish initiation of plus-strand DNA synthesis. Ty1 elements bearing a mutated PPT2 sequence are not defective for transposition whereas mutations in PPT1 abolish transposition.
\end{abstract}

yeast / Ty elements / reverse transcriptase / RNA primers / transposition

\section{Introduction}

The Ty transposable elements (Ty1 to Ty5) are a family of retrotransposons found in the yeast Saccharomyces cerevisiae [1]. They are structurally and functionally similar to eukaryotic retroviruses in that they alternate their genetic material between RNA and DNA [2, 3] and contain a large internal domain flanked on either side by direct long terminal repeats (LTRs). The most abundant member of the yeast retrotransposon family is Ty 1 [4-6], a 5.9-kb element consisting of a central coding region called epsilon $(\varepsilon)$ flanked by two long terminal repeats of $334 \mathrm{bp}$ called delta $(\delta)$ (fig $1)$. The $\varepsilon$ region is composed of two open reading frames [7], TyA which encodes the nucleocapsid protein of Ty1 virus like particles (VLPs) and TyB which encodes proteins with protease, integrase, reverse transcriptase and RNase $\mathrm{H}$ activities. The $\delta$ region comprises the unique $3^{\prime}$ (U3), the repeat (R) and the unique $5^{\prime}$ (U5) sequences. The life cycle of Ty elements begins with transcription of the integrated

*Correspondence and reprints

Abbreviations: LTR, long terminal repeat; VLP, virus like particle; PBS, primer binding site; PPT, polypurine tract. retrotransposon DNA; the retrotransposon DNA is transcribed from one LTR to the other to form a terminally redundant transcript which is shorter than the retrotransposon DNA and organized as R-U5-E-U3-R. The Ty transcript is then packaged into the intracytoplasmic virus-like particles where it is converted into double-stranded DNA by

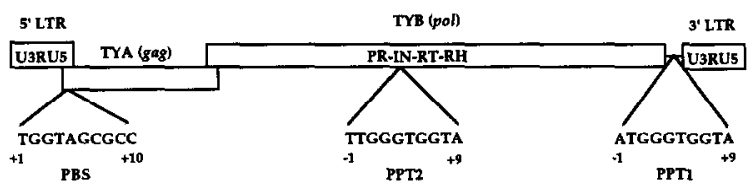

Fig 1. Structure of the Ty1 retrotransposon. The yeast Saccharomyces cerevisiae Tyl retrotransposon is a $5.9 \mathrm{kbp}$ long element consisting of a central region with two open reading frames TyA equivalent to the gag gene of retroviruses and TyB equivalent to pol gene of retroviruses, flanked by two long terminal repeats (LTRs). There is an overlap between the 5' LTR and TyA and between the TyA and TyB open reading frames. Arrangement of the enzymatic activities on the TyB gene is indicated: PR, protease; IN, integrase; RT- $\mathrm{RH}$, reverse transcriptase with a $\mathrm{RNase} \mathrm{H}$ activity. Positions and sequences of the PBS and of the two PPTs in the Tyl genome are indicated. Position -1 of PPT1 and PPT2 corresponds to position 5576 and 3782 of the Ty $1-\mathrm{H} 3$ sequence respectively [6]. 
the process of reverse transcription (fig 2) $[8,9]$. Both strands of the retrotransposon DNA are synthesized by the retrotransposon reverse transcriptase which is able to utilize both RNA and DNA as template. Like other DNA polymerases, reverse transcriptase has an absolute requirement for primers to initiate DNA synthesis: a specific host tRNA is used as a primer to initiate minus-strand cDNA synthesis; plus-strand DNA synthesis is initiated from an RNase $\mathrm{H}$ resistant oligoribonucleotide spanning a purine-rich sequence, the polypurine tract (PPT).

Some features of minus-strand and plus-strand DNA synthesis of the yeast retrotransposon Ty 1 will be discussed below.

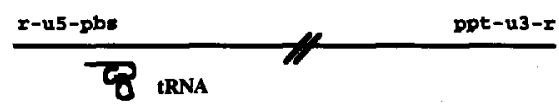

The primer tRNA is annealed to the PBS (primer binding site).

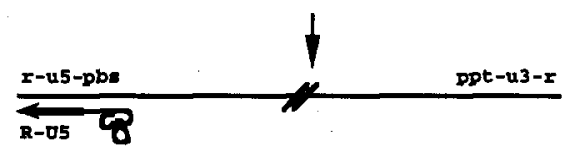

First strand transfer: The 5 ' end of the genomic RNA is degraded. Strong-stop cDNA $(-)$ is translocated to the $3^{\prime}$ end of the genomic RNA

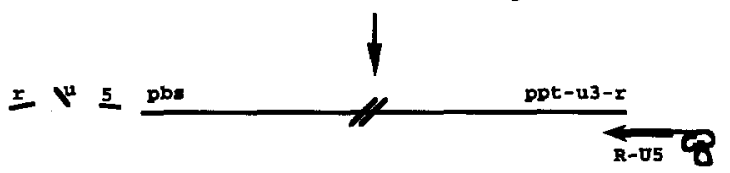

The translocated nascent $c D N A(-)$ is extended. The genomic RNA template is deguaded and removed except for the PPT (polypurine tract) fragment.

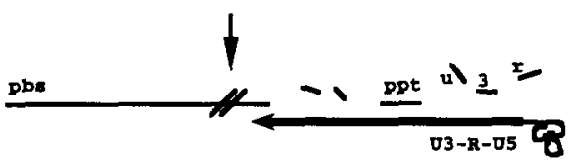

Plus-strand DNA synthesis is initiated from the PPT fragment.

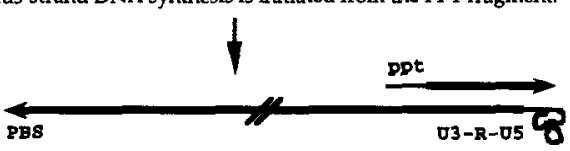

Second strand transfer: The nascent DNA(+) is translocated to the end of the CDNA(-).

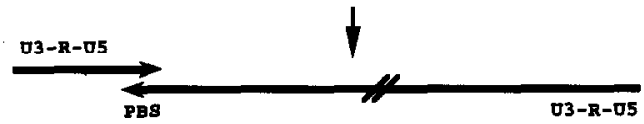

Reverse transcriptase completes DNA synthesis.

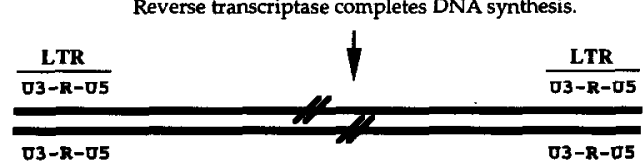

Fig 2. Synthesis of retrotransposon double-stranded DNA.

\section{Initiation of minus-strand cDNA synthesis of Ty1}

Methionine initiator tRNA primes minus-strand cDNA synthesis

The primer tRNA used to initiate minus-strand cDNA synthesis is selected from the pool of cellular tRNAs and packaged along with the genomic RNA into the VLPs. Conversion of the genomic RNA molecule to its double stranded DNA copy via reverse transcription takes place in the cytoplasmic VLPs. To initiate reverse transcription the primer tRNA must be unwound to form a duplex with a specitic region of the Tyl RNA called the primer binding site (PBS) located near the $5^{\prime}$ end of the genomic RNA. cDNA synthesis proceeds from the $3^{\prime}$-hydroxyl end of the primer and is halted when reverse transcriptase reaches the $5^{\prime}$ end of the genomic RNA template. The PBS region of Ty1 is complementary to the $3^{\prime}$ terminus of the acceptor stem of the yeast initiator methionine transfer RNA (tRNA $\mathrm{A}_{\mathrm{i}} \mathrm{Met}$ ). Direct isolation, separation and sequencing of the tRNA molecules associated with Ty1 VLPs indicates that tRNA ${ }_{i}$ Met is 10 -fold enriched in VLPs compared with the level of this tRNA in a total cellular extract [10].

Recent work by Chapman et al [11] has directly demonstrated the role of $\mathrm{tRNA}_{\mathrm{i}}{ }^{\mathrm{Met}}$ in priming Ty1 reverse transcription. A yeast strain in which the four endogenous tRNA $_{i}$ Met genes had been disrupted and complemented by a cloned tRNA ${ }_{i}$ Met gene was used to characterize mutations in the Tyl element and $t \mathrm{RNA}_{\mathrm{i}}{ }^{\mathrm{Met}}$ primer that affect transposition. A Ty1 element with mutations in the PBS sequence that changed five of the 10 nucleotides complementary to the tRNA ${ }_{i}{ }^{M e t}$ was constructed. Transposition frequency was dramatically reduced in a strain carrying this mutant Ty 1 element suggesting that the nucleotide sequence of the PBS region in Ty 1 is essential for transposition. To unambiguously demonstrate the requirement for complementarity between the PBS and the tRNA ${ }_{i}$ Met for Ty1 transposition, changes complementary to the mutant PBS were introduced into the acceptor stem of the tRNA $\mathrm{A}_{\mathrm{i}}{ }^{\mathrm{Met}}$. A strain carrying both the mutant Tyl element and the tRNA ${ }_{i}$ Met with the compensatory mutations in its acceptor stem was shown to be able to transpose. These results provided strong evidence that complementarity between the 10 nucleotides at the $3^{\prime}$ terminus of tRNA ${ }_{i}{ }^{\text {Met }}$ and the PBS of Ty1 RNA was absolutely required for priming Ty1 reverse transcription and demonstrated that $\mathrm{RNA}_{\mathrm{i}} \mathrm{Met}^{\text {Met }}$ was essential for Ty 1 transposition.

\section{Extended interactions between the primer $t R N A$ and genomic RNA of the yeast retrotransposon TyI}

Recent experimental data obtained with the Tyl element and several retroviruses [12-17] suggest that interactions between the primer tRNA and genomic RNA are not limited to base pairing between the $10-18$ nucleotides at the $3^{\prime}$ end of the tRNA and the complementary PBS. We have made a 
structural probing study of the tRNA ${ }_{i}$ Met-Tyl RNA binary complex and proposed a secondary structure model of the complex consistent with our probing data [18] (fig 3). This model shows that besides interactions between the PBS and the $3^{\prime}$ end of the tRNA ${ }_{i}$ Met, three short regions of the Ty1 RNA named box 0 , box 1 and box 2.1 interact with the T and $\mathrm{D}$ stems and loops of the tRNA $\mathrm{A}_{i}{ }^{\mathrm{Met}}$. Another region of Ty1 RNA (box 2.2), located 20 nucleotides downstream of box 2.1, has the same sequence as box 2.1 but does not interact with the tRNA ${ }_{i}{ }^{\text {Met. }}$. To test our model, specific nucleotides changes were made in box 0 , box 1 and box 2.1 or in the complementary sequences of the tRNA ${ }_{i}$ Met to study the contribution of these sequences on the formation of the complex [18]. We have found that interaction with box 0 or box 1 is absolutely required for efficient annealing of the two RNAs. The role of box 2.1 does not seem to be as crucial for formation of the complex. Although it has not been possible to probe the structure of the tRNA $\mathrm{A}_{\mathrm{i}} \mathrm{Met}_{-} \mathrm{Ty} 1$ RNA initiation complex in vivo, some experimental evidence suggests that the extended tRNA ${ }_{i}{ }^{M e t}$-Ty1 RNA interactions play a role in vivo. We have previously shown that mutations in the boxes result in defective transposition of the Ty1 element [19]. In keeping with our results, Keeney et al [20] have found that mutations in the $\mathrm{T}$ arm and loop of the tRNA ${ }_{i}{ }^{M e t}$ at nucleotides 54,60 and 54/60 affect transposition frequency. The fact that these mutations disrupt

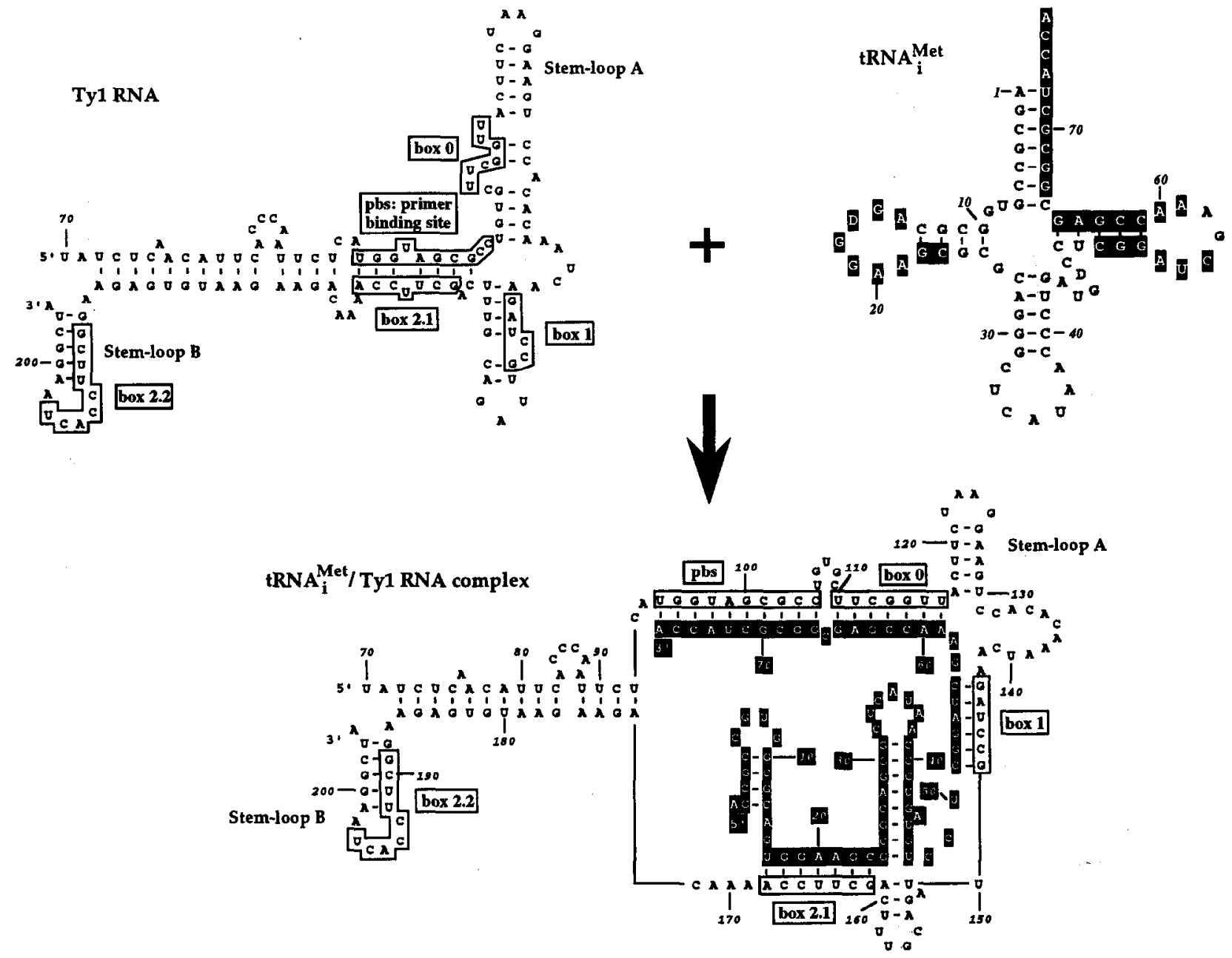

Fig 3. Secondary structure model of the Tyl RNA, $\operatorname{tRNA}_{i}{ }^{\text {Met }}$ and Ty 1 RNA-tRNA ${ }_{i}^{\text {Met }}$ binary complex. The PBS is complementary to ten nucleotides at the $3^{\prime}$ end of the tRNA ${ }_{i}^{\text {Met }}$. Boxes $0,1,2.1$ and 2.2 are complementary to parts of the T and D stems and loops of the tRNA ${ }_{i}^{\text {Met }}$. The regions of tRNA ${ }_{i}^{\mathrm{Met}}$ complementary to the PBS and the boxes are indicated in black in the secondary structure of the tRNA ${ }_{i}^{\mathrm{Met}}$. In the tRNA $_{i}{ }^{\text {Met }}$-Ty1 RNA complex all the nucleotides of the RNA $_{i}{ }^{\text {Met }}$ have been black-boxed. 
some of the base pairs between the tRNA $\mathrm{i}_{\mathrm{i}}^{\mathrm{Met}}$ and box 0 and/or box 1 could explain the transposition defective phenotype of the mutants. This is consistent with our in vitro results showing the importance of box 0 and box 1 for annealing of $\mathrm{tRNA}_{i}{ }^{\mathrm{Met}}$ with Ty1 RNA. Keeney et al [20] have also tested whether Arabidopsis thaliana or Schizosaccharomyces pombe initiator tRNAs could serve as primers for retrotransposition. These tRNAs were mutated so that their acceptor stem would be complementary to the Ty1 PBS. It was found that the resulting $A$ thalian a hybrid tRNA was able to support transposition whereas the $S$ pombe hybrid tRNA was not. Sequence comparison of the two hybrid tRNAs with $S$ cerevisiae $t R N A$ suggested that a determinant important for the priming function was located in the D arm of the tRNA. Indeed, sequence of the D arm is similar in $S$ cerevisiae $\mathrm{tRNA}_{\mathrm{i}}{ }^{\text {Met }}$ and $A$ thaliana $\mathrm{tRNA} \mathrm{A}_{\mathrm{i}}{ }^{\text {Met }}$ but differs in $S$ pombe hybrid tRNA $\mathrm{i}^{\text {Met }}$ which is not able to support transposition. Interestingly, the $3^{\prime}$ part of the $\mathrm{D}$ arm of $t R N A_{i}$ Met interacts with box 2.1 of Tyl RNA in our structural model of the tRNA ${ }_{i}$ Met-Tyl RNA complex. Examination of the Tyl sequence shows that only five out of seven nucleotides of Ty1 box 2.1 could interact with the D stem of $S$ pombe hybrid tRNA ${ }_{i}$ Met. This would destabilize the interaction between box 2.1 of Tyl RNA and the hybrid tRNA $\mathrm{i}_{\mathrm{i}}^{\mathrm{Met}}$. We speculate that the disruption of some of the Watson-Crick base pairs in the tRNA ${ }_{i}$ Met-Ty 1 RNA complex would alter its structure which would no longer be able to serve as an initiation complex. This suggests that extended interactions between the primer tRNA $_{i}{ }^{\text {Met }}$ and the genomic Tyl RNA produce a specific orientation of the RNA secondary structure preferentially recognized by reverse transcriptase. It would now be interesting to determine which steps of the priming process are affected by the secondary structure of the tRNA ${ }_{i}{ }^{\text {Met-Ty1 } 1 \text { RNA complex. }}$

\section{Initiation of plus-strand DNA synthesis of Ty1: two sites, PPT1 next to the $3^{\prime}$ LTR and PPT2 within the pol gene, are used to prime plus-strand synthesis}

The predominant initiation site of plus-strand DNA synthesis of LTR retroelements is located near the $3^{\prime}$ end of the genome at the $5^{\prime}$ boundary of the long terminal repeat $[21$, 22]. The plus-strand primer is a specific purine-rich fragment of RNA called PPT (polypurine tract) generated after minus-strand DNA synthesis has proceeded beyond the U3/PPT boundary. During minus-strand DNA synthesis, most of the genomic RNA is released from the nascent minus-strand DNA after degradation by RNase $\mathrm{H}$ except for the primer PPT fragment which is not degraded and remains annealed to the minus-strand DNA. Plus-strand DNA synthesis proceeds from this primer, using the minus-strand DNA as a template. Most retroviruses utilize several plusstrand priming sites [23-27]. Characterization of subgenomic DNA fragments of Ty1 suggests that two sites are employed for plus-strand DNA synthesis of Ty1 [28]. Two putative primers have been identified by primer extension experiments: PPT1 located at the $5^{\prime}$ boundary of the $3^{\prime}$ LTR and PPT2 located near the middle of the pol gene in the integrase coding region. Interestingly, the two putative PPTs have an identical sequence, TGGGTGGTA, which is rather different from the 18 to 23 nucleotides long retroviral polypurine tract or from the PPT sequence found in Ty 3 [29]. To provide direct evidence that this sequence is required for priming of Ty1 plus-strand DNA synthesis, the effect of mutations introduced in PPT1 and PPT2 on plusstrand synthesis was analyzed [30]. Details of these mutations are shown in figure 4B. By Southern blot analysis of the DNA fragments present in mutant VLPs, we found that specific nucleotide changes introduced in PPT1 or PPT2 diminish or abolish the amount of plus-strand initiated at the mutated site. The result of a typical experiment is shown in figure $4 \mathrm{C}$. In cells containing the wild type Ty 1 element, two major fragments of $0.345 \mathrm{~kb}$ and $3.0 \mathrm{~kb}$ and a minor fragment of about $1.0 \mathrm{~kb}$ were detected (fig $4 \mathrm{C}$, lane W). The $0.345 \mathrm{~kb}$ fragment is the plus-strand strong-stop DNA initiated at PPT1. The $3.0 \mathrm{~kb}$ fragment is the plus-strand DNA fragment initiated at PPT2 spanning the $3^{\prime}$ half of the Tyl genome. The minor $1.0 \mathrm{~kb}$ fragment has not been identified. The Southern blot shown in figure $4 \mathrm{C}$ reveals that mutations in PPT sequences affect plus-strand DNA synthesis. The synthesis of the $3.0 \mathrm{~kb}$ fragment is strongly reduced in PPT2 mutant 73 (fig 4C, lane 73) and is abolished in PPT2 mutant 74 (fig 4C, lane 74). Some mutations introduced in the PPT1 sequence inhibit the synthesis of the $0.345 \mathrm{~kb}$ fragment (fig $4 \mathrm{C}$, lane 98 ). For a double mutant (mutant 74-98) in which PPT1 and PPT2 were mutated, the syntheses of the $0.345 \mathrm{~kb}$ and $3.0 \mathrm{~kb}$ fragments are both inhibited (fig 4C, lane 74-98). In contrast, the $\mathrm{T}$ to $\mathrm{C}$ nucleotide change introduced at position +1 in PPT1 mutant 99 does not reduce the intensity of the signal given by the 0.345 $\mathrm{kb}$ fragment (fig $4 \mathrm{C}$, lane 99), indicating that this $\mathrm{T}$ residue is not important for priming from PPT1. We conclude from these experiments that the two PPT sequences previously identified are indeed used as primers for initiation of plusstrand synthesis and that the nucleotide sequence of the PPT is important for its priming function.

We have also examined the role of PPT mutations on transposition. As shown in table I the level of transposition of the two PPT2 mutants (73 and 74) is close to that of the wild type Ty1 element. Since the synthesis of the $3.0 \mathrm{~kb}$ plus-strand is weakened in PPT2 mutant 73 VLPs and abolished in PPT2 mutant 74 VLPs we conclude that the plus-strand fragment initiated at PPT2 is not absolutely required for Tyl transposition. In contrast, mutation 98 in PPT1 that abolishes plus-strand strong-stop DNA synthesis also renders Ty1 elements defective for transposition (the relative transposition of mutant 98 is 0.05 compared to 1 for the wild type element; fig 4). The crucial role of PPT1 in transposition can be explained by the fact that accurate initiation at this site is essential to generate the correct left hand of the upstream LTR which contains cis-acting se- 
A

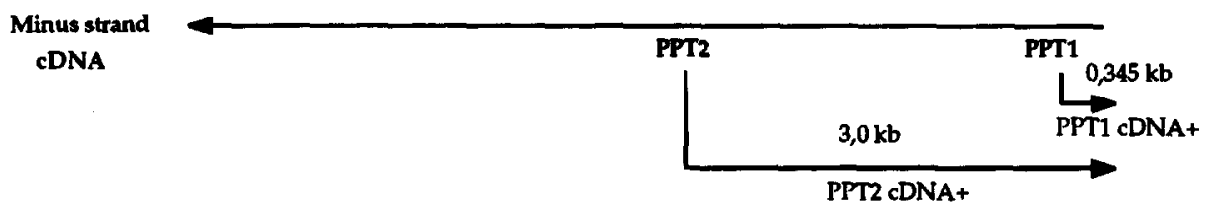

B

\begin{abstract}
PYT2

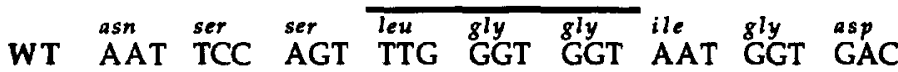

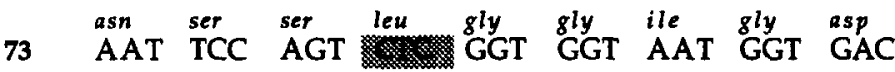

74 AAT $\stackrel{\text { ser }}{\text { TCC }}$ AGT leu gly ala ile
\end{abstract}

Relative transposition frequency ( $\%$ of wild type)

100

70

80

100

79

5

C

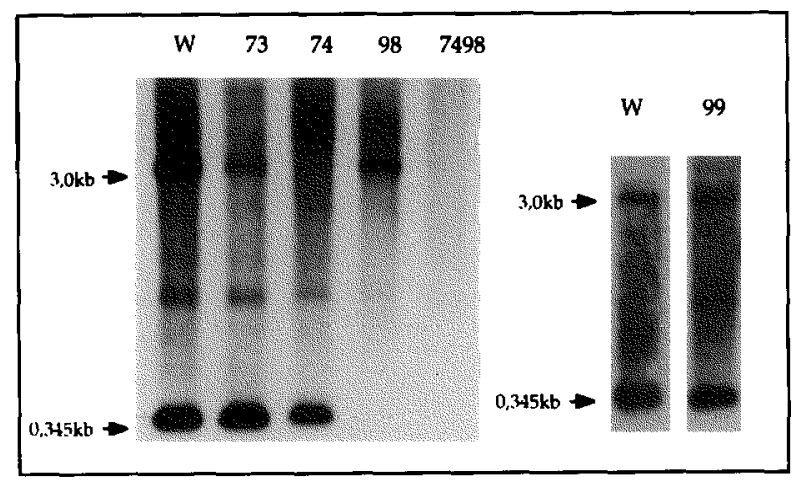

Fig 4. Effect of mutations in the PPT sequence on plus-strand DNA synthesis and transposition. A. The positions of PPT1 and PPT2 in the genome of Ty1 are indicated. For the Tyl element used in this study the length of the plus-strand initiated at PPT1 and PPT2 is $0.345 \mathrm{~kb}$ and $3.0 \mathrm{~kb}$ respectively. B. Details of the mutations introduced in PPT1 and PPT2. The amino acid sequence of the PPT2 region is indicated. In PPT2 mutant 74, a GGT codon is changed into GCT leading to the replacement of a glycine by an alanine residue. PPT1 is in the $3^{\prime}$ non-coding region of the Ty1 sequence. The effect of PPT mutations on transposition is indicated. C. Southern analysis of plus-strand DNA in Tyl wild type and mutant VLPs. 
Table I. Transposition frequency of wild type and PPT mutant Tyl elements. The PPT mutations were incorporated in a GALTy1 element marked with neo to quantitate transposition. Transposition of the marked element into the host genome confers resistance to G418. Transposition was induced by growth at $22^{\circ} \mathrm{C}$ on YNB medium complemented with the required amino acids and containing $2 \%(\mathrm{w} / \mathrm{v})$ galactose. After 5 days the cells were plated as single colonies to non-selective medium YPD to allow for plasmid loss. Following 2 days of growth at $30^{\circ} \mathrm{C}$ the plates were replica-plated to a YNB medium containing $1 \mathrm{mg} 5$-fluoroorotic acid $/ \mathrm{mL}, 50 \mu \mathrm{g}$ uracil $/ \mathrm{mL}$ and the required amino acids to select for cells that have lost the plasmid containing the URA3 gene. After 2 days of growth at $30^{\circ} \mathrm{C}$, the plates were replicated to YPD medium containing $75 \mu \mathrm{g}$ of $\mathrm{G} 418 / \mathrm{mL}$ and to YNB medium containing the required amino acids and $2 \%(\mathrm{w} / \mathrm{v})$ glucose to identify colonies ( $\mathrm{Neo}^{\mathrm{r}} \mathrm{Ura}^{-}$) that had undergone transposition of the Tyl-neo element.

Tyl elements Transposition frequencies
$(\%)$

PPT2 mutants

Wild type

PPT2 inutant 73

PPT2 mutant 74

27.2

19.1

22.2

PPTl mulants

Wild type

PPT1 Inutant 99

PPT1 mutant 98

PPT1-PPT2 double mutant

PPT1/2 mutant 74-98

0.4

quences required for integration of retrotransposon DNA into the host cellular DNA.

\section{Conclusion}

Within the past 10 years, yeast Ty elements have been used as models to study retrotransposon replication. We have discussed some features of two crucial steps of the Ty1 replication process: the initiation of minus-strand and plus-strand DNA synthesis. Much is still unknown about the mechanism of reverse transcription priming. For example, we do not know how the primer tRNA is selected and packaged into VLPs or how it is unwound to anneal to the PBS. We know that base pairing between the boxes or the PBS of Tyl RNA and the primer $\mathrm{tRNA}_{i}$ Met plays a role in $\mathrm{tRNA}_{\mathrm{i}} \mathrm{Met}$ packaging [19]. However, other factors may be involved in the selection of the primer tRNA. A role for reverse transcriptase and for nucleocapsid protein in primer tRNA incorporation into avian, murine and human retroviruses (ASLV, MuLV and HIV-1) was inferred from in vitro and in vivo experiments (for a review see [31]). It was also suggested that these two proteins could promote annealing of the replication primer tRNA to the initiation site and subsequently facilitate elongation [31]. In the yeast system it is not known whether the Ty 1 reverse transcriptase and/or the TyA encoded nucleocapsid protein play a similar role for packaging or annealing of the tRNA.

We have demonstrated that plus-strand DNA synthesis of the yeast Tyl element is initiated at two sites located at the $5^{\prime}$ boundary of the $3^{\prime}$ LTR and near the middle of the TyB (pol) gene. We have shown that the two PPTs have an identical sequence, TGGGTGGTA, and that mutations in this sequence affect plus-strand priming. However, the sequence by itself is not sufficient to generate a plus-strand origin since two identical sequences located in other regions of the genome are not used as primers. Thus, it is possible that the recognition signal for specific primer formation and elongation also lies in the overall conformation or secondary structure of the PPT domain and not only in the nucleotide sequence of the primer.

One unresolved aspect of initiation of plus-strand synthesis is the mechanism by which RNase $\mathrm{H}$ activity of reverse transcriptase cleaves the RNA at a specific site at the end of the PPT to generate the exact plus-strand primer terminus. Extensive in vitro studies with defined DNA-RNA hybrid substrates and purified reverse transcriptases from vertcbratc retroviruses indicate that the spccificity of cleavage is not intrinsic to the structure of the PPT alone and that a correct positioning of $\mathrm{RNase} \mathrm{H}$ plays a role in the specific cleavage at the end of the PPT region [21]. It is clear that further studies will be needed to determine the sequence or structural features important for the positioning of the RNase $\mathrm{H}$. It will also be interesting to know whether other factors are required to create a functional plus-strand primer.

A last question which should be addressed, is the role of the second plus-strand start site found near the middle of the genome. Our results show that synthesis of plus-strand primed by the internal PPT is not required for Ty1 replication and transposition. What then is the biological role of the second origin of Ty1 DNA plus-strand synthesis? It has been speculated that initiation of DNA plus-strand synthesis at multiple sites could contribute to retroviral recombination [32]. It was proposed that during reverse transcription, single stranded branches displaced from the minus-strand cDNA copied from one genome in the virion might anneal to an homologous region of the minus-strand cDNA copied from the second RNA genome in the virion, giving rise to a heteroduplex [33]. Although there is no direct evidence that two genomic RNA molecules are packaged into Ty 1 VLPs, this assumption is supported by the results of genetic experiments suggesting that recombinant progeny elements derive from the reverse transcription of different RNA molecules packaged inside the same virus like particle [34]. The possibility that DNA plus-strand displacement during Ty1 reverse transcription is involved in the generation of hybrid progeny elements must now be investigated. 
Given the advantages of the yeast system, we expect that molecular, biochemical and genetic approaches will provide answers to some of the questions concerning the priming of reverse transcription of Ty elements and lead to a better understanding of the replication of eukaryotic retroelements.

\section{Acknowledgments}

This work was supported in part by grants from the Association pour la Recherche contre le Cancer (ARC) and from the Ligue Nationale contre le Cancer, Comité Départemental du Haut-Rhin.

\section{References}

1 Boeke JD, Sandmeyer S (1991) Yeast transposable elements. In: The Molecular and Cellular Biology of the Yeast Saccharomyces cerevisiae (Broach JR, Jones EW, Pringle J eds) Cold Spring Harbor Laboratory Press, 193-261

2 Varmus H (1988) Retroviruses. Science 240, 1427-1435

3 Boeke JD, Garfinkel DJ, Styles CA, Fink GR (1985) Ty elements transpose through an RNA intermediate. Cell 40, 491-500

4 Clare J, Farabaugh P (1985) Nucleotide sequence of a yeast Ty element: evidence for an unusual mechanism of gene expression. Proc Natl Acad Sci USA 82, 2829-2833

5 Warmington JR, Waring RB, Newlon CS, Indge KJ, Oliver SG (1985) Nucleotide sequence characterization of Ty1-17, a class II transposon from yeast. Nucleic Acids Res 13, 6679-6693

6 Boeke JD, Eichinger D, Castrillo D, Fink GR (1988) The Saccharomyces cerevisiae genome contains functional and nonfunctional copies of transposon Ty1. Mol Cell Biol 8, 1432-1442

7 Adams SE, Mellor J, Gull K, Sim RB, Tuite MF, Kingsman SM, Kingsman AJ (1987) The functions and relationships of Ty-VLP proteins in ycast reflects those of mammalian retroviral protcins. Cell 49, 111-119

8 Eichinger DJ, Boeke JD (1988) The DNA intermediate in yeast Ty1 element transposition copurifies with virus-like particles: cell-free Ty 1 transposition. Cell 54, 955-966

9 Mellor J, Fulton SM, Dobson MJ, Wilson W, Kingsman SM, Kingsman AJ (1985) A retrovirus-like strategy for expression of a fusion protein encoded by yeast transposon Ty1. Nature 313, 243-246

10 Pochart P, Agoutin B, Fix C, Keith G, Heyman T (1993) A very poorly expressed tRNA ${ }^{\text {Ser }}$ is highly concentrated together with replication primer initiator tRNA $i$ in the yeast Ty1 virus-like particles. Nucleir Acids Res 21, 1517-1521

11 Chapman KB, Byström AS, Boeke JD (1992) Initiator methionine tRNA is essential for Tyl transposition in yeast. Proc Natl Acad Sci USA 89, 3236-3240

12 Haseltine WA, Kleid DG, Panet A, Rothenberg E, Baltimore D (1976) Ordered transcription of RNA tumor virus genomes. J Mol Biol 106, 109-131

13 Cordell B, Swanstrom R, Godman HM, Bishop JM (1979) tRNA ${ }^{\text {Trp }}$ as primer for RNA-directed DNA polymerase: structural determinants and function. $J$ Biol Chem 254, 1866-1874

14 Aiyar A, Ge Z, Leis J (1994) A specific orientation of RNA secondary structure is required for initiation of reverse transcription.J Virol 68,611-618

15 Aiyar A, Cobrinik D, Zheng GE, Kung HJ, Leis J (1992) Interaction between retroviral U5 RNA and the TYC loop of the tRNA ${ }^{\text {TrP }}$ primer is required for efficient initiation of reverse transcription. $J$ Virol 66 , 2464-2472

16 Leis J, Aiyar A, Cobrinik D (1993) Regulation of initiation of reverse transcription of retroviruses. In: Reverse transcriptase (Skalka AM, Goff SP, eds) Cold Spring Harbor Laboratory Press, 33-47

17 Isel C, Ehresmann C, Keith G, Ehresmann B, Marquet R (1995) Initiation of reverse transcription of HIV-1: secondary structure of the HIV-1 RNA/tRNA ${ }^{\text {Lys }}{ }_{3}$ (template/primer) complex. J Mol Biol 247, 236-250

18 Friant S, Heyman T, Wilhelm ML, Wilhelm FX (1996) Extended interactions between the primer tRNA ${ }^{\text {iMet }}$ and genomic RNA of the yeast Tyl retrotransposon. Nucleic Acids Res 24, 441-449

19 Wilhelm M, Wilhelm FX, Keith G, Agoutin B, Heyman T (1994) Yeast Ty1 retrotransposon: the minus-strand primer binding site and a cis-acting domain of the Ty1 RNA are both important for packaging of primer tRNA inside virus-like particles. Nucleic Acids Res $22,4560-4565$

20 Keeney JB, Chapman KB, Lauermann V, Voytas DF, Äström SU, Von Pawel-Rammingen U, Byström A, Boeke JD (1995) Multiple molecular determinants for retrotransposition in a primer tRNA. Mol Cell Biol $15,217-226$

21 Champoux JJ (1993) Roles of ribonuclease $\mathrm{H}$ in reverse transcription. In: Reverse transcriptase (Skalka AM, Goff SP, eds) Cold Spring Harbor Laboratory Press, 103-118

22 Telenitsky A, Goff SP (1993) RNase H domain mutations affect the interaction between moloney murine leukemia virus reverse transcriptase and its primer-template. Proc Natl Acad Sci USA 90, 1276-1280

23 Charneau P, Clavel F (1991) A single-stranded gap in human immunodeficiency virus unintegrated linear DNA defined by a central copy of the polypurine tract. $J$ Virol $65,2415-2421$

24 Charneau P, Alizon M, Clavel F (1992) A second origin of DNA plusstrand synthesis is required for optimal immunodeficiency virus replication. I Virol 66, 2814-2820

25 Harris JD, Scott JV, Traynor B, Brahic M, Stowring L, Ventura P, Haase AT, Peluso R (1981) Visna virus DNA: Discovery of a novel gapped structure. Virology 113, 573-583

26 Blum HE, Harris JD, Ventura P, Walker D, Staskus K, Retzel E, Haase AT (1985) Synthesis in cell culture of the gapped linear duplex DNA of the slow virus visin. Virology 142, 270-277

27 Boone LR, Skalka AM (1993) Strand displacement synthesis by reverse transcriptase. In: Reverse Transcriptase (Skalka AM, Goff SP, eds) Cold Spring IIarbor Laboratory Press, 1 19-133

28 Pochart P, Agoutin B, Rousset S, Chanet R, Doroszkiewicz V, Heyman $T$ (1993) Biochemical and electron microscope analyses of the DNA reverse transcripts present in the virus like particles of the yeast transposon Ty1. Identification of a second origin of Ty1 DNA plus-strand synthesis. Nucleic Acids Res 21, 3513-3520

29 Hansen JL, Chalker DL, Sandmeyer SB (1988) Ty3, a yeast retrotransposon associated with tRNA genes, has homology to animal retroviruses. MolCell Biol 8, 5245-5256

30 Heyman T, Agoutin B, Friant S, Wilhelm FX, Wilhelm M (1995) Plusstrand DNA synthesis of the yeast retrotransposon Ty1 is initiated at two sites, PPT1 next to the $3^{\prime}$ LTR and PPT2 within the pol gene. PPT1 is sufficient for Tyl transposition. J Mol Biol 253, 291-303

31 Darlix JL, Lapadat-Tapolski M, de Rocquigny H, Roques BP (1995) First glimpses at structure-function relationships of the nucleocapsid protein of retroviruses. $J$ Mol Biol 254, 523-537

$32 \mathrm{Hu}$ WS, Temin HM (1990) Retroviral recombination and reverse transcription. Science 250, 1227-1232

33 Junghans RP, Boone LR, Skalka AM (1982) Products of reverse transcription in avian retrovirus analyzed by electron microscopy. Cell 30 , $53-62$

34 Boeke JD, Styles CA, Fink GR (1986) Saccharomyces cerevisiae SPT3 gene is required for transposition and transpositional recombination of chromosomal Ty elements. Mol Cell Biol 6, 491-500 